\title{
INCLUÍDOS PELA ESCOLA PÚBLICA: TRAJETÓRIA SOCIAL DE EGRESSOS TRÂNSFUGAS DO COLÉGIO ESTADUAL DIAS VELHO (SEGUNDA METADE DA DÉCADA DE 1960) ${ }^{1}$
}

\author{
Juliana Maués Silva Clarino ${ }^{2}$ \\ Norberto Dallabrida ${ }^{3}$
}

\section{RESUMO}

Este trabalho tem por objetivo analisar a trajetória social de três egressos trânsfugas do curso clássico do Colégio Estadual Dias Velho - estabelecimento de ensino secundário de caráter público, gratuito e coeducativo -, destacando os fatores sociais que concorreram para o êxito nas suas carreiras profissionais. Os trajetos sociais desses ex-alunos de escola pública são construídos a partir de conceitos cunhados por Pierre Bourdieu, tais como os conceitos de habitus, capital cultural, capital social e trânsfuga, procurando relacionar a origem social, o percurso escolar e a carreira profissional. O corpus documental do presente trabalho é formado por dados colhidos a partir de aplicação de um questionário e, especialmente, por meio de uma entrevista semiestruturada realizada com os três egressos em análise.

Palavras-chave: Trajetória social; trânsfuga; ensino secundário; escola pública.

\section{INCLUDED IN THE PUBLIC SCHOOL: SOCIAL TRAJECTORY OF EGRESSES TURNCOATS FROM STATE COLLEGE DIAS VELHO (SECOND HALF OF THE 1960's)}

\begin{abstract}
This paper intends to analyze the social trajectory of three egresses turncoats of the classic course of the State College Dias Velho - secondary school, public, free and of coeducative character - highlighting the social factors that contributed to the success in their careers. The social trajectories of these former students are built from concepts coined by Pierre Bourdieu, such as the concepts of habitus, cultural capital, social capital and turncoats, linking social origin, educational background and professional career. The documentary corpus of this study consists of data collected from a questionnaire and especially by means of a semistructured interview with the three graduates in analysis.
\end{abstract}

Keywords: Social trajectory; Turncoats; High School; Public School.

\section{Introdução}

Com a implantação dos cursos clássico e científico, no início de 1950, constituía-se o Colégio Estadual Dias Velho (CEDV) na cidade de Florianópolis (Santa Catarina), que funcionava no prédio do instituto de educação homônimo. $O$ processo de implantação do ensino secundário no Instituto de Educação Dias Velho havia iniciado no começo do ano letivo de 1947, quando terminara o contrato entre o Governo do Estado de Santa Catarina e a Companhia de Jesus, que impedia a implantação do ensino secundário público e gratuito no território catarinense e foi criado o curso ginasial na Escola Normal Pedro II de 
Blumenau e nos institutos de educação de Lages e de Florianópolis. Assim, a partir da década de 1950, o CEDV passou a oferecer os dois ciclos do ensino secundário - ginasial e colegial -, fato que reestruturava o subcampo do ensino secundário em Florianópolis. Em meados do século XX, a acanhada capital catarinense tinha somente dois estabelecimentos de ensino secundário de caráter privado e distintos em gêneros: o Colégio Catarinense, dirigido por padres jesuítas e voltado para adolescentes homens, e o Colégio Coração de Jesus, coordenado pelas Irmãs da Divina Providência e direcionado para adolescentes mulheres. O ensino secundário instalado no Instituto de Educação Dias Velho oportunizava o acesso a esse nível de escolarização a filhos e filhas de grupos sociais que não pertenciam às elites, especialmente as classes médias.

Nos anos 50 do século XX, o ensino secundário brasileiro era prescrito pela lei orgânica do ensino secundário, um decreto-lei instituído em 1942, que tinha a marca do então Ministro da Educação e da Saúde, Gustavo Capanema. Segundo essa lei imposta em plena ditadura getulista, esse nível de escolarização destinava-se à formação das "elites condutoras" da sociedade em franco desenvolvimento, sendo subdividido em dois ciclos: o primeiro, constituído pelo curso ginasial, comum a todos os estudantes, e o segundo, alcunhado de colegial, era formado por dois cursos - o clássico e o científico -, permitindo aos alunos uma escolha (SAVIANI, 2010, p. 269 ). A diferenciação entre esses dois cursos paralelos era mais de ordem teórica na medida em que os alunos que pretendiam ingressar em carreiras profissionais nas áreas de ciências naturais e exatas realizavam o científico e aqueles que almejavam realizar estudos superiores de Direito e na área de humanidades formavam-se no curso clássico. Sobre essa matização, Souza, (2008, p. 182) conclui que:

A diferença que há entre eles, dizia Capanema, é que, no primeiro (o clássico), a formação intelectual dos alunos é marcada por um acentuado estudo das letras antigas, ao passo que, no segundo (o científico), a maior acentuação cultural é proveniente do estudo das ciências. Entretanto a conclusão tanto de um como de outro dará direito ao ingresso em qualquer modalidade de curso do ensino superior.

Em relação aos cursos do colegial, isto é, o segundo ciclo do ensino secundário, os educandários de Florianópolis se diferenciavam, de forma que os colégios confessionais tinham somente o curso científico e em regime de internato e externato, que funcionavam durante o dia, enquanto o CEDV oferecia os cursos clássico e científico somente no período noturno. O curso científico encaminhava particularmente para o ensino superior distinto, representado pelos cursos de medicina e engenharia, que, nos anos 1950, não eram oferecidos na capital catarinense. Para realizar esses cursos superiores era necessário dispor de significativos recursos financeiros, fato que bloqueava as classes desfavorecidas, e viver em outras capitais brasileiras, o que geralmente se convertia numa dificuldade para as mulheres. O curso clássico do CEDV era frequentado por número menor de estudantes, de modo coeducativo, e seus alunos geralmente ingressavam em cursos oferecidos em faculdades localizadas em Florianópolis como Direito e Filosofia, que tinham menor prestígio no campo do ensino superior. (DALLABRIDA, 2012). Assim, a escolha do curso do ciclo colegial tinha geralmente uma implicação de pertencimento a grupos sociais privilegiados e do gênero masculino.

Como instituição escolar pública, gratuita e coeducativa, nos anos 1950, o CEDV era constituído por um corpo docente selecionado por concurso público e, por isso, bastante diversificado, formado por professores católicos, espíritas, comunistas e inclusive 
por um padre grego. O seu alunado era formado por adolescentes homens e mulheres de grupos sociais que não podiam pagar um estabelecimento de ensino privado e que geralmente trabalhava durante o dia e/ou não desejavam receber uma educação católica. Nesta direção, este trabalho procura analisar a trajetória social de três alunos egressos do curso clássico do CEDV da década de 1950, que realizaram curso superior e construíram carreiras profissionais exitosas. Eles se chamam Alcides dos Santos Aguiar, Cláudio Andrade Ramos e Álvaro Wandelli Filho, considerados trânsfugas de classe que, segundo Bourdieu (1998b), são indivíduos que rompem a sua condição de classes social e ascendem socialmente por meio de muito esforço e renúncia e/ou mediadores sociais diversos, tais como o estímulo de um professor ou o pertencimento a uma associação política ou comunitária, e mormente por meio da escolarização prolongada.

A trajetória social é entendida como a relação entre a origem sociofamiliar, o percurso escolar e a carreira profissional dos agentes sociais. Essa análise está ancorada na perspectiva "sócio-lógica" de Pierre Bourdieu (1998e), que flagra as desigualdades sociais e escolares a partir de uma visão polimorfa do capital. Segundo Nogueira e Catani (1998), o conceito de capital cultural é entendido como as formas de cultura adquiridas pelos agentes sociais, seja no estado incorporado, quando o indivíduo internaliza disposições duráveis, seja no estado objetivado de bens culturais (livros, quadros, etc.) ou no estado institucionalizado, materializado por meio de diplomas e certificados escolares. Para Bourdieu (1998d, p. 74), na forma incorporada, "o capital cultural é um ter que se tornou ser, uma propriedade que se fez corpo e tornou-se parte integrante da 'pessoa', um habitus". Por isso, na obra desse sociólogo francês, o conceito de habitus tem uma importância fulcral para a análise de trajetórias de agentes sociais.

O conceito de capital social é entendido como "[...] o conjunto de recursos atuais ou potenciais que estão ligados à posse de uma rede durável de relações mais ou menos institucionalizada de interconhecimento e inter-reconhecimento [...]". (BOURDIEU, 1998c, p. 67). Ou seja, neste caso, trata-se de relações que os sujeitos estabelecem durante a convivência familiar, no percurso escolar e na carreira profissional e que podem lhe ser úteis na construção no êxito de seu trajeto social. Sendo assim, pensaremos em como o capital cultural internalizado tanto através de uma herança parental quanto por relações sociais e/ou investimentos ao longo de seu percurso pode ter interferido nas trajetórias sociais dos egressos aqui analisados. O capital informacional também é um conceito importante para analisar trajetórias de trânsfugas porque o acesso às informações privilegiadas por parte de pais, parentes, amigos ou professores pode fazer a diferença na escolarização prolongada e/ou nas carreiras profissionais. Na perspectiva bourdieusiana, o conceito de Montagner (2007, p. 18), oportuno para a nossa investigação, afirma:

Em suma, perseguir uma trajetória significa acompanhar o desenrolar histórico de grupos sociais concretos em um espaço social definido por esses mesmos grupos em suas batalhas pela definição dos limites e da legitimidade dentro do campo em que se inserem. Seguramente a origem social é um holofote poderoso na elucidação dessas trajetórias, pois o habitus primário, devido ao ambiente familiar, é uma primeira e profunda impressão social sobre o indivíduo, que sofrerá outras sedimentações ao longo da vida.

A escolha dos três egressos que são analisados sociologicamente no presente trabalho foi feita a partir de respostas de questionários enviados para os ex-alunos do CEDV que concluíram o ensino secundário na década de 1950. O questionário abordava 
questões que versavam sobre a origem sociofamiliar, o percurso escolar e a carreira profissional dos alunos egressos, enfatizando coligir dados sobre a trajetória social dos exalunos. Com cada um dos três egressos selecionados foi feita uma entrevista semiestruturada com o intuito de reafirmar e confrontar as informações colhidas nos questionários, mas especialmente para aprofundar informações relevantes e detalhadas, como a ordem moral doméstica e os mediadores sociais, que concorreram para a sua ascensão social por meio da conclusão do ensino secundário. Os egressos assinaram termos de consentimento de uso de nome, divulgação da entrevista bem como, uso da imagem se assim fosse necessário.

\section{Alcides Aguiar: capital informacional e mãe mediadora social}

Nascido em 1939, Alcides dos Santos Aguiar construiu todo o seu percurso escolar, tanto em nível primário quanto nos dois níveis do ensino secundário, no CEDV onde formou-se, no ano de 1957, no curso clássico. Em nível superior realizou estudos na Faculdade de Filosofia e, posteriormente, concluiu o curso de direito na Universidade Federal de Santa Catarina (UFSC). Fez carreira jurídica no sistema público e aposentou-se como desembargador do estado de Santa Catarina.

O egresso vivenciou e assistiu aos esforços de seus pais para intentar maior acúmulo de capital econômico e cultural, o que se daria através de uma mudança de residência da sua família do distrito de Ingleses para o centro de Florianópolis, onde passou a infância e adolescência. Quando houve a mudança de bairro, a principal renda da sua família era oriunda do pai que se inseriu na atividade comercial e, posteriormente, oriunda tanto do pai quanto da mãe que se tornaram funcionários públicos. O egresso fala dos pais como pessoas que se organizaram em todos os momentos para que os filhos pudessem estudar, envolvendo-os sempre nas atividades domésticas e agregando informações em seus ambientes profissionais que viessem a se converter em melhores possibilidades escolares e profissionais para os filhos. Sobre a importância da ordem moral doméstica para a gestão da família e da escolarização dos filhos, Lahire (1997, p. 26) afirma:

Se a ordem moral e material em casa pode ter uma importância na escolaridade dos filhos, é porque é, indissociavelmente, uma ordem cognitiva. A regularidade das atividades, dos horários, as regras de vida escritas e recorrentes, os ordenamentos, as disposições ou classificações domésticas produzem estruturas cognitivas ordenadas, capazes de pôr ordem, gerir, organizar os pensamentos.

De acordo com o declarado no questionário, em termos de capital econômico, a família de Alcides era originalmente pertencente à classe popular, porém é possível constatar no decorrer da entrevista, uma gradual ascensão da família nos primeiros anos de vida dos dois filhos. O pai, que tinha ensino primário, era pescador, mas logo em seguida ingressou no comércio e depois fez carreira profissional no funcionalismo público no Tribunal de Justiça, sendo considerado pelo egresso um lutador. Já a mãe, que chegou a concluir o curso normal, fez carreira como funcionária pública da Assembléia Legislativa e é caracterizada pelas falas do filho como mais culta e inclinada para os estudos. (AGUIAR, 2012). 
As falas do egresso sobre os pais, especificamente sobre os hábitos familiares nos fazem inferir que a figura paterna significou para ele um exemplo de homem pragmático, como ele mesmo disse, que zelava pela casa que haviam conseguido com empréstimo bancário e se empenhava em trabalhar para manter a família em melhores condições da que um dia ele teve. Quanto à figura materna, Alcides se referiu sempre como portadora de maior capital cultural, com "mais estudo", fato que a fez tomar a dianteira no que diz respeito ao estímulo para que os filhos seguissem o caminho dos estudos, o que nos faz pensá-la também como mediadora social. O egresso salienta que se fosse pelo pai, ambos os filhos seriam "lutadores", do comércio, ideia que mudou após os filhos seguirem para o ensino superior. Segundo ele, a figura materna representava forte influência e estímulo para a vida escolar dos filhos, pois afirma que "ela cobrava, exigia, fiscalizava, via os boletins, conversava com os professores, procurava professor particular pra nós". (AGUIAR, 2012, p. 9-10).

Ainda sobre a influência e vigilância materna, verificamos que, no decorrer da entrevista, o egresso considera fundamental para toda a sua trajetória o curso de taquigrafia que fez por exigência da mãe, ainda na época em que cursava o curso clássico no CEDV. Esse curso, além de ter tido muita serventia durante sua vida acadêmica, converteu-se em instrumento de trabalho, pois, em 1959, após muitos testes, conseguiu o emprego de taquígrafo na Assembléia Legislativa do estado de Santa Catarina. Assim, o capital informacional da mãe adquirido em seu ambiente de trabalho foi, segundo Alcides, de fundamental importância e, de fato, viabilizou oportunidades profissionais para o egresso.

Serão abordados agora os caminhos percorridos por Alcides para a construção de sua trajetória de "sucesso" tanto no percurso escolar quanto no campo profissional. O egresso fala com relativa naturalidade da transição do ensino primário para o ensino secundário. Esta percepção pode ser analisada pelo viés do capital informacional conferido pelo fato de ter feito o ensino primário em um prédio anexo ao CEDV, saber da oferta daquela modalidade de ensino e ver a emergência do ensino secundário tão de perto, sendo considerado um fator importante em sua trajetória. Segundo ele, todo o seu estudo e do irmão foi no CEDV, declarando: "Eram quatro anos de primário, depois vinha o Instituto de Educação Dias Velho que era o Ginásio, mais quatro anos, também no mesmo prédio, e após o Colégio Dias Velho, que era a terceira fase, a última etapa, desde o [Ensino] Fundamental até o Médio". (AGUIAR, 2012, p. 4). Sobre isso Nogueira e Nogueira (2009, p. 53) dizem:

Vale ainda destacar a importância de um componente específico do
capital cultural, constituído pelo capital de informações sobre a estrutura
e os modos de funcionamento do sistema de ensino ("uma das mediações
através das quais o sucesso escolar - e social - se vincula à origem
social" - Bourdieu, 1997, p.42). Não se trata aqui apenas do
conhecimento maior ou menor que se possa ter da organização formal do
sistema escolar (ramos de ensino, cursos, estabelecimentos), mas,
sobretudo, da compreensão que se tem das hierarquias mais ou menos
sutis que distinguem as ramificações escolares do ponto de vista de sua
qualidade acadêmica, prestígio social e retorno financeiro.

Aguiar concluiu o curso primário e fez o exame de admissão para ter acesso ao ensino ginasial. Sobre esse momento de sua trajetória, o egresso não menciona nenhum esforço específico e inclusive, ao ser questionado sobre como se deu a passagem do curso ginasial no CEDV para o curso clássico, afirmou que esta etapa se tratava de uma 
continuidade, uma vez que era clara a sua predileção pelas letras e pelas humanidades. Em algumas passagens da entrevista é possível perceber que mesmo não tendo feito esforços excessivos, o percurso escolar não foi necessariamente linear, sem rupturas ou obstáculos. Alcides afirma que em determinado momento do curso ginasial apresentou dificuldades em matemática e a sua mãe fez esforços para pagar professores particulares para que o filho superasse essa dificuldade. O egresso afirma também que, no segundo ano do curso ginasial, foi reprovado em inglês, por preferir praticar futebol em detrimento do estudo da língua inglesa. (AGUIAR, 2012, p.5 - 6).

Além dessas passagens que imprimem certas dificuldades no percurso escolar e os esforços maternais para a superação das mesmas, o egresso relata também ter tido dificuldades quando na transição da vida escolar para a vida universitária. Alcides relata não ter sido aprovado no primeiro concurso vestibular que tentou, o que indica um momento de instabilidade em sua vida estudantil. Em 1958, após formar-se no curso clássico, Aguiar intenta os vestibulares de direito e filosofia, mas, não obtendo aprovação no primeiro curso superior, inicialmente matriculou-se na Faculdade de Filosofia. No ano seguinte e desta vez com sucesso, conseguir a aprovação no vestibular para o curso de direito na UFSC. O egresso atribui o fato de não ter conseguido ingressar nesse curso superior na primeira tentativa à dificuldade da prova de francês, que era parte do vestibular.

A carreira profissional de Alcides iniciou-se em 1959, durante o primeiro ano do curso de direito, quando, utilizando-se das habilidades da taquigrafia, conseguiu ingressar na "Assembléia Legislativa [de Santa Catarina] a título precário, ganhando cinco mil cruzeiros naquela época, como taquígrafo". (AGUIAR, 2012, p.6). Ele trabalhou nessa função até 1963, quando se formou e passou a atuar como advogado durante algum tempo e, em seguida, ingressar como assessor jurídico do Tribunal de Justiça, fator que considera como um "degrau definitivo" para definição de sua carreira no campo jurídico. (AGUIAR, 2012, p. 12). Nesse mesmo ano, Alcides casou-se com Lourdes, sua atual esposa e, no ano seguinte prestou o concurso para juiz de direito e foi aprovado, iniciando a sua carreira de magistrado pelo interior de Santa Catarina. Posteriormente também foi aprovado para desempenhar a função de desembargador do Tribunal de Justiça de Santa Catarina, na qual se aposentou.

Quanto ao êxito de sua carreira profissional, alguns fatores são apontados por Aguiar como decisivos, como o fato dos seus pais trabalharem como funcionários públicos - a mãe na Assembléia Legislativa e o pai no Tribunal de Justiça - e estarem em constante contato com concursos públicos e atividades relacionadas aos setores judiciário e legislativo. O pai também é citado como figura que contribuiu sobremaneira para a construção da sua trajetória profissional na medida em que o dissuadiu a fazer o concurso para a carreira bancária, concurso que planejava tentar em 1962, às vésperas de terminar o curso de direito. Para ele, o pai fizera aquilo com a intenção de que seu curso universitário não fosse sacrificado e não acabasse desistindo da carreira na área de direito.

As formas familiares de investimento pedagógico que encontramos na organização da família de Alcides imprimem a existência de um "projeto" ou de uma "intenção familiar" inteiramente voltada para escola e para o êxito dos filhos. Aguiar configura-se como trânsfuga de classe, na medida em que seu pai, inicialmente pescador, e sua mãe modesta funcionária pública, fizeram investimentos e uniram esforços para propiciar a ele e ao irmão condições de estudo que os pudessem projetar para carreiras profissionais de maior prestígio, o que possibilitou a ambos ascensão nos campos nos quais ingressaram. 


\section{Cláudio Ramos: capital cultural e social herdados do pai}

Nascido em 31 de Janeiro de 1939 em Lages, interior de Santa Catarina, Cláudio Andrade Ramos foi o primeiro filho entre os três herdeiros de Maria Luiza Andrade Ramos e Jaime Arruda Ramos. A família dele mudou-se para o município de São José - vizinho a Florianópolis - quando ele tinha oito anos de idade, pelo fato de seu pai ficar sem emprego fixo. Em São José, Cláudio conclui os estudos primários no Grupo Escolar Francisco Tolentino, educandário ao qual atribui a aquisição de boa base para o ingresso posterior no curso ginasial do CEDV.

O pai de Cláudio não dispunha de capital econômico suficiente para manter os filhos em colégios particulares e, durante a sua vida, não acumulou razoável volume de bens materiais. A intensa atividade política do pai viabilizou a tessitura de um círculo de amizade de prestígio, de modo que a sua família tinha acúmulo de excelente capita social. Porém, ao analisar origem social e familiar do estudante Cláudio, constamos que o capital econômico de seus pais era, de fato, modesto. Seu percurso escolar parece ter transcorrido com certa tranqüilidade, pois fez o curso de admissão para adentrar no CEDV sem freqüentar curso preparatório. Mais especificamente, na passagem para do curso ginasial para o curso clássico, Cláudio nos diz que o fato de ter dificuldades nas áreas de exatas como em física, química e matemática - levou-o a fazer essa opção no ciclo colegial, bem como também escolher o curso de direito para construir sua carreira profissional. Por outro lado, constatamos que seu pai tinha grande acúmulo de capital cultural porque atuava como jornalista freelancer, escrevendo sobre política nos jornais catarinenses, fato que fez Cláudio tomar certa familiaridade com as práticas de leitura e escrita. Seus irmãos mais novos, ao contrário, não cursaram ensino superior, talvez por terem crescido com o pai já tendo ingressado no funcionalismo público. Ele recorda:

Meu pai era jornalista, escrevia nos jornais 'A Gazeta' e 'Diário da Tarde'. O irmão dele, também jornalista, era diretor do jornal 'O Estado'. Meu pai era da UDN, meu tio do PSD, eles eram super amigos, mas militavam em partidos diferentes. Meu pai lia, diariamente 'O Jornal' do Rio de Janeiro, 'Diário de Notícias' e 'Tribuna da Imprensa' ambos do Rio. Eu sempre lia estes três jornais que ele comprava, sempre gostei de ler [...]. (RAMOS, 2012, p. 4).

Nos anos 50 do século XX, Cláudio herdou capital cultural e social por parte do pai jornalista e do tio diretor de jornal. Esse traço de sua disposição foi constatado no momento da realização da entrevista, pois em sua casa eram visíveis as influências da cultura letrada materializada no grande volume de livros, filmes e revistas dispostos visivelmente na sala. Assim, possuidor herdeiro do capital cultural em estado objetivado, ou seja, convertido em bens materiais, a exemplo de livros e escritos, Cláudio adquire um habitus leitor, que o confere facilidade em relação às práticas de ensino-aprendizagem nas instituições escolares, bem como aquisição de conhecimento de uma forma geral.

Quando da passagem do ensino secundário para o curso superior, pudemos constatar, assim como na trajetória do egresso analisado anteriormente, que foi naquele momento que emergiu o primeiro obstáculo imposto para a trajetória social do ex-aluno em análise. Na primeira tentativa de ingresso no curso superior de direito, via vestibular, o egresso não obteve "sucesso" por não ter alcançado os critérios de aprovação em língua 
latina. Assim, durante um ano, ele frequentou o curso de história da Faculdade de Filosofia, que foi interrompido com a sua aprovação no concurso vestibular para o curso de direito da UFSC.

Cláudio iniciou a sua carreira profissional na Secretaria de Justiça quando ainda era estudante do curso clássico, o que o ajudou a se afeiçoar à cultura jurídica, de forma que ele se enquadra na rotina daquele aluno da escola pública que trabalha de dia e estuda à noite. Antes de formar-se em direito, prestou concurso para fiscal de tributos da Secretaria da Fazenda, cargo no qual consolidou sua carreira e aposentou-se e pelo qual desiste da área escolhida no ensino superior. Após concluir o ensino superior em 1964, Cláudio não atua como advogado, pois já está imerso nas atividades de fiscal da Secretaria da Fazenda, viajando inclusive para viver no interior do estado de Santa Catarina. Sua carreira profissional, bem como os cargos e postos de trabalho por ele alcançados, são fruto não só de seu empenho individual, mas também do capital cultural e social que acumulou durante sua trajetória social, particularmente na família. Além de jornalista e funcionário público, seu pai mantinha relações políticas estreitas com a elite política da UDN, partido que dominou o executivo catarinense nos anos 1950, bem como mantinha boas relações com políticos de outros partidos. Assim, avaliamos que o pouco volume de capital econômico da sua família foi compensado pelo intenso acúmulo de capital cultural e social por parte do seu pai.

A sua trajetória social permite concluir que Cláudio é também um caso de trânsfuga de classe na medida em que ele faz parte de uma família remediada, mas com um pai com excelente capital cultural e uma rede útil de relações sociais. A intensa atividade política do "chefe" da família pode ser considerada como um mediador social de decisiva importância para a manutenção e ascensão da família Ramos, contribuindo para a exitosa trajetória social de Cláudio.

\section{Álvaro Wandelli Filho: importância do capital cultural e da filosofia esotérica}

Oriundo do Rio de Janeiro, Álvaro Wandelli Filho, converteu-se em um desafiador objeto de estudos na medida em que, no momento da entrevista, as suas respostas foram sucintas e cuidadosas. Contudo, aos poucos foi possível constatar que a origem social de sua numerosa família, composta pelo pai, mãe e oito filhos, não seria abordada com aprofundamento, o que dificultou a análise acurada de sua origem sociofamiliar. De todo modo, verificamos que seus pais tinham capital econômico relativamente escasso, pois o pai era um corretor de imóveis, que, após Álvaro sair de casa, torna-se funcionário público, e a mãe dedicava-se ao lar.

Álvaro foi um trânsfuga precoce, pois saiu de casa muito cedo. Seu percurso escolar pelo curso primário feito no Rio de Janeiro na escola pública República do Peru, o curso de admissão para o ciclo ginasial realizado na Fundação Gama Filho, segundo ele "um estabelecimento escolar antigo e muito conhecido no Rio de Janeiro, inclusive o seu diretor principal tinha sido Ministro da Educação do Brasil" (WANDELLI FILHO, 2012, p.2), e o curso ginasial concluído em um Colégio Ténico-Agrícola que funcionava em regime de internato. É no ginásio que Wandelli Filho dá os primeiros passos rumo à emancipação tanto cultural quanto econômica, pois lá o egresso descobre o prazer pela leitura. Neste processo de aproximação com a leitura é que ele afirma ter descoberto que seu caminho profissional não era nem na Agronomia e nem na Veterinária, áreas para as quais a instituição em que ele então estudava preparava seus alunos. Ocorreu, então, o 
despertar de seu interesse pelas humanidades e o planejamento precoce de intentar a carreira na área de direito. Neste momento da passagem do curso ginásio para o curso colegial é possível perceber a necessidade de o egresso de custear os planos que havia traçado de entrar na faculdade de direito. Neste contexto Wandelli faz um curso técnico de meteorologia para ter condições financeiras de custear seus planos e estudos. (WANDELLI FILHO, 2012, p. 2)

Formado em meteorologia, Álvaro começou a trabalhar em aeroportos como meteorologista da Aeronáutica e, nessa profissão, aos dezoito anos, é transferido do Rio de Janeiro para Porto Alegre, onde já passa a ter sua própria vida financeira e concilia o trabalho com os estudos no curso clássico do Colégio Julio de Castilhos. Na metade do segundo ano do colegial na capital sul-rio-grandense, Wandelli Filho é, mais uma vez, transferido para trabalhar como meteorologista no aeroporto Hercílio Luz de Florianópolis, passando a estudar no curso clássico do CEDV. Por outro lado, ele afirma que herdou do pai livros de religiões esotéricas pelos quais tem grande apego e aos quais atribui grande parte do sucesso que alcançou na carreira profissional. Em se tratando de capital cultural familiar, pôde-se então asseverar que quando esse egresso do CEDV saiu da casa dos pais para fazer o curso ginasial no internato, bem como quando se distancia do estado do Rio de Janeiro por causa do seu trabalho, leva consigo esse pequeno acervo da modesta biblioteca do pai e faz desses livros seus preciosos bens espirituais. Ele recorda esse detalhe importante da sua vida, afirmando:

Eu quero dizer que as leituras e estudos do meu pai me serviram posteriormente. Eu levei alguns livros do acervo do meu pai, tal como livros de filosofia. Ele era filiado à Editora do Pensamento, que publicava livros sobre o pensamento filosófico, que eu chamaria de esotérico, obras como: BhagavadGîta, O Evangelho de Buda e Uma Aventura na Mansão dos Adeptos Rosa-Cruzes, que foi uma obra que marcou a minha formação. Mal eu sabia que mais tarde eu seria membro da Ordem Rosacruz Amorc, da qual sou filiado até hoje. [...] Livros assim deste tipo que, quando fui morar sozinho, levei comigo do acervo do meu pai, que foram os primeiros livros que me deram sustentação nas minhas pesquisas básicas na área da Filosofia, pois sempre gostei muito desse ramo do conhecimento. (WANDELLI FILHO, 2012, p. 4).

Durante a realização da entrevista, o seu apreço pela leitura de livros esotéricos ficou evidente e parece ser o leitmotiv na trajetória social de Álvaro. Quando questionado sobre a sua motivação para os estudos, a determinação para perseguir os seus ideais e até a influência dos seus pais em seu percurso escolar e carreira profissional, fica claro que ele atribui a si mesmo todo o esforço e determinação, pois diz: "Eu sempre senti dentro de mim uma tendência para progredir, para estudar, para saber. Aliás, a entrada na escola de sabedoria arcaica, como é a Ordem Rosacruz Amorc, reflete esta tendência íntima". (WANDELLI FILHO, 2012, p. 5). Desse modo, pode-se concluir que a filosofia esotérica e a Ordem Rosacruz Amorc tenham funcionado como mediadores sociais que sustentaram e contribuíram para consolidar a ascensão social e profissional do ex-aluno em análise.

Sobre seus estudos no CEDV, Álvaro relembra o período com saudosismo latente, pois a forma como fala especialmente dos colegas demonstra que, naquele período em que morava sozinho, trabalhava e estudava longe da família, os colegas do curso clássico, assim como as leituras e o afinco nos estudos, foram as formas encontradas para estabelecer-se em Florianópolis e escolher essa cidade para residir. Segundo o egresso “[...] 
a companhia da juventude de colegas que caminharam conosco em nossa trajetória, sempre foi muito prazerosa e serviu para nos estimular a trabalhar e perseguir estas metas nobres de uma profissão superior e 'vencer' na vida". (WANDELLI FILHO, 2012, p. 7). Ainda sobre a época que fez o curso clássico, Álvaro rememora que fez parte do grêmio estudantil como orador oficial e que teve uma breve vida político estudantil na instituição, escrevia para a seção literária do jornal "O Estado". Na sua autoavaliação, ele acredita que era "um jovem que estava buscando aprofundar-se e conhecer mais e mais". (WANDELLI FILHO, 2012, p. 3).

A progressão profissional aconteceu de maneira natural. Ainda trabalhando como meteorologista no Aeroporto Hercílio Luz, fez concurso para promotor de justiça do estado do Paraná, desta forma, deixou de trabalhar na Aeronáutica e iniciou carreira jurídica. Após quatro meses trabalhando no Paraná, fez o mesmo concurso para o estado de Santa Catarina e, então, já casado e com filhos, rumou para o oeste catarinense e começou a trabalhar e construir nova carreira. Em 1967, faz concurso para juiz de direito e começou a carreira de magistrado, passagem que aproxima a sua carreira profissional a carreira do primeiro egresso aqui analisado, pois, mais tarde, Álvaro também foi promovido a desembargador da justiça de Santa Catarina. Além da carreira na magistratura, em alguns momentos o egresso trabalha como professor, revelando também inclinação para a docência. Segundo ele, trabalhou no ensino médio da Escola Industrial de Florianópolis como professor de português, no curso normal da Escola Mater Dolorum de Capinzal, como professor de história, na Universidade do Sul de Santa Catarina e na Escola Superior da Magistratura de Florianópolis, como professor de direito.

A carreira profissional de Álvaro revela sua inclinação para o acúmulo de capital cultural, objetivado inicialmente pela biblioteca que herdou do pai, que levou consigo quando saiu de casa e que guarda até hoje com apreço e carinho. Esse capital cultural incorporado na família foi sendo desdobrado e enriquecido na sua vida estudantil devido à sua participação no grêmio estudantil e a seção literária do "Jornal O Estado", bem como na publicação de poesia e de filosofia esotérica ${ }^{4}$. Esses aspectos à disposição de Álvaro para os bens culturais, filosóficos e literários própria das humanidades de um profissional do direito.

\section{Considerações finais}

As análises histórico-sociológicas empreendidas a partir das entrevistas realizadas com os três egressos formados no curso Clássico do CEDV na década de 1950 levam-nos a concluir que se tratam de trânsfugas de classe na medida que ascenderam socialmente devido à realização do ensino secundário em escola pública. Ou seja, a posição social alcançada por eles com a construção de carreiras profissionais em cargos públicos e profissões de prestígio, que viabilizou acúmulo de capitais econômico, escola e cultural é, efetivamente, superior à condição sócioeconômica de seus pais.

A origem sociofamiliar dos trânsfugas é inicialmente distinta para cada um dos casos, mas as suas trajetórias sociais ganham contornos parecidos quando os trajetos sociais cruzam seus caminhos no percurso escolar no CEDV. Alcides, Cláudio e Álvaro concluíram no mesmo ano o curso clássico e, na realização das entrevistas, afirmaram que são amigos até hoje. Os três concluíram o Curso de Direito, cuja preparação ideal no ensino secundário era feita no curso clássico, que dava certa ênfase nas letras e humanidades. O primeiro e o último construíram carreira jurídicas de destaque porque 
tornaram-se desembargadores no estado de Santa Catarina e o segundo atuou profissionalmente como fiscal de tributos da Secretaria da Fazenda no Estado de Santa Catarina, que não deixa de ser uma carreira pública de destaque para a qual os seus conhecimentos jurídicos foram de grande valia.

Em relação aos mediadores sociais que concorreram para que cada um dos egressos concluísse o ensino secundário e realizassem carreiras exitosas, constatamos diferentes configurações sociofamiliares. Para Alcides a mãe teve um papel decisivo porque tinha um capital escolar superior ao pai e acompanhou, de modo vigilante, o percurso escolar dos filhos. Cláudio herdou do pai, jornalista freelancer, que acumulou relações políticas úteis e prestigiosas, importantes capitais cultural e social, que, em boa medida, auxiliaram-no na sua carreira profissional. Álvaro o capital cultural-filosófico paterno imprimiu marcar indelével no seu habitus. Álvaro teve o seu habitus marcado pela filosofia esotérica, que se materializou particularmente para herança da biblioteca paterna, que lhe proporcionou o amor aos livros, alavancando o acúmulo de capital cultural e sua fluência na realização de cursos secundário e superior. Essa influência cultural foi tão decisiva na vida de Álvaro, de modo que até os dias atuais ele participa da filosofia esotérica Rosacruz Amorc.

Com a análise desses três perfis, foi possível reafirmar os postulados bourdieusianos a respeito da importância do capital cultural nas trajetórias sociais devido ao fato de concorrerem para processos de escolarização de longo prazo. Alcides, Cláudio e Álvaro, originários de classes socialmente desfavorecidas, converteram-se em trânsfugas de classe social pelo fato de concluírem o ensino secundário em escola pública. Contudo, deve-se registrar que esses egressos que tiveram êxito sócio-profissional devido a fatores sociofamiliares específicos, configuram-se como os poucos casos miraculosos de inclusão social por meio da escola pública.

\section{Referências}

AGUIAR, Alcides dos Santos. Entrevista concedida a Juliana Maués S. Clarino. Pesquisa "Trajetórias sociais de egressos/as dos colégios de ensino secundário de Florianópolis na década de 1950”. Florianópolis, 16 de Fev. de 2012. Entrevista transcrita. 15 p. 2012.

BOURDIEU, Pierre. A escola conservadora: as desigualdades frente à escola e à cultura. Trad. Aparecida Joly Gouveia. In: NOGUEIRA, Maria Alice; CATANI, Afrânio (Orgs.). Escritos de Educação. Petrópolis, RJ: Vozes, 1998a, p. 39-64.

As contradições da herança. Trad. Magali de Castro. In: NOGUEIRA, Maria Alice; CATANI, Afrânio (Orgs.). Escritos de Educação. Petrópolis, RJ: Vozes, 1998b, p. 229-237.

. O capital social - notas provisórias. Trad. Denice Barbara Catani e Afrânio Mendes Catani. In: NOGUEIRA, Maria Alice; CATANI, Afrânio (Orgs.). Escritos de Educação. Petrópolis, RJ: Vozes, 1998c, p. 65-69.

Os três estados do capital cultural. Trad. Magali de Castro. In: NOGUEIRA, Maria Alice; CATANI, Afrânio (Orgs.). Escritos de Educação. Petrópolis, RJ: Vozes, 1998d, p. 71-79.

La distinción: criterio y bases sociales del gusto. Madrid: Taurus, 1998e.

DALLABRIDA, Norberto. Usos sociais da cultura escolar prescrita no ensino secundário. Revista Brasileira de História da Educação. Campinas - SP, v. 12, n. 1 (28), p. 167-192, jan./abr. 2012. 
LAHIRE, Bernard. Sucesso escolar nos meios populares: as razões do improvável. São Paulo: Ática, 1997. Tradução de Ramon Américo Vasques e Sonia Goldefeder.

MONTAGNER, Miguel Ângelo. Trajetórias e biografias: notas para uma análise bourdieusiana. Sociologias. Porto Alegre - RS, n.17,jan./jun. 2007, p. 240-264.

NOGUEIRA, Maria Alice; NOGUEIRA, Claudio Martins. Bourdieu \& a Educação. Belo Horizonte, MG: Autêntica, 2009.

NOGUEIRA, Maria Alice; CATANI, Afrânio. Uma sociologia da produção do mundo cultural e escolar. In: NOGUEIRA, Maria Alice; CATANI, Afrânio (Orgs.). Escritos de Educação. Petrópolis, RJ: Vozes, 1998, p. 7-15.

RAMOS, Claudio Andrade. Entrevista concedida a Juliana Maués S. Clarino. Pesquisa "Trajetórias sociais de egressos/as dos colégios de ensino secundário de Florianópolis na década de 1950". Florianópolis, 28 de Mar. de 2012. Entrevista transcrita. 10 p. 2012.

SAVIANI, Demerval. História das Ideias Pedagógicas no Brasil. Campinas, SP: Autores Associados, 2010.

SOUZA, Rosa Fátima de. História da organização e do currículo no século XX: ensino primário e secundário no Brasil. São Paulo: Cortez, 2008.

WANDELLI FILHO, Álvaro. Entrevista concedida a Juliana Maués S. Clarino. Pesquisa "Trajetórias sociais de egressos/as dos colégios de ensino secundário de Florianópolis na década de 1950”. Florianópolis, 27 de Jun. de 2012. Entrevista transcrita. 07 p. 2012.

\section{Notas}

\footnotetext{
${ }^{1}$ Este artigo é resultado parcial da pesquisa "Trajetórias sociais de egressos/as dos colégios de ensino secundário de Florianópolis na década de 1950", apoiada pela Universidade do Estado de Santa Catarina (UDESC) e pelo CNPq.

${ }^{2}$ Acadêmica do Curso de Pedagogia do Centro de Ciências Humanas e da Educação da UDESC, bolsista de Iniciação Científica PIBIC/CNPq. Universidade do Estado de Santa Catarina. Endereço eletrônico: ju.maues@yahoo.com.br

${ }^{3}$ Professor do Programa de Pós-Graduação em Educação da UDESC e bolsista produtividade do CNPq. Universidade do Estado de Santa Catarina. Endereço eletrônico: norbertodallabrida@ hotmail.com

${ }^{4}$ Salvemos Nosso Lar Planetário, um livro em colaboração com vários escritores e ambientalistas onde reuni inúmeros ensaios [...] um deles de minha autoria." (WANDELLI FILHO, 2012, p. 6). Esta obra tem o nome completo de "Salvemos Nosso Lar Planetário: uma introdução ao estudo da questão ambiental", mais informações sobre a obra e o autor disponíveis em: http://direito2.com/tjsc/2006/jun/28/desalvaro-wandellifilho-lanca-obra-sobre-questao-ambiental, acesso em 29 julho 2012.
}

Recebido em março-13

Aprovado em setembro-13 